\title{
Manipulation of task constraints on throwing of amateur handball athletes
}

\author{
GABRIEL A. RIBEIRO' ${ }^{1}$ PEDRO H. B. F. SPINOLA | HELGA T.TUCCI ${ }^{1}$ | RAQUEL P. CARVALHO1
}

${ }^{1}$ Federal University of Sao Paulo (Unifesp), Department of Human Movement Science, Santos, SP, Brazil.

Correspondence to: Raquel de Paula Carvalho. Av. Ana Costa, 95, Vila Mathias - 11060-001 - Santos-SP, Brazil.

email: carvalho.raquel@unifesp.br

https://doi.org/10.20338/bjmb.v15i2.198

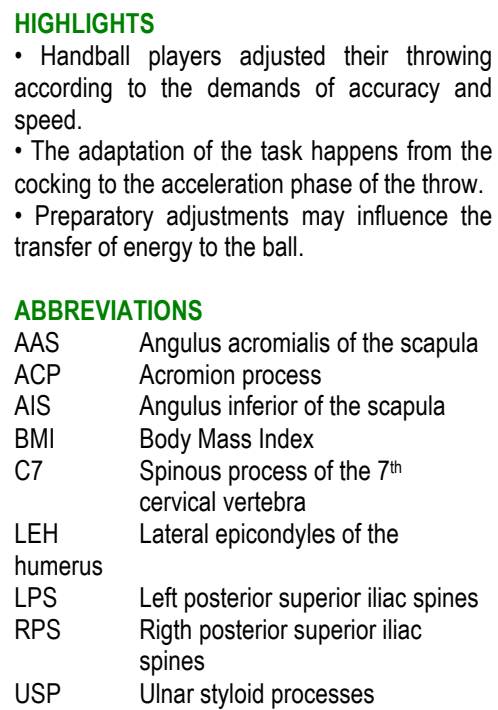

- Handball players adjusted their throwing according to the demands of accuracy and speed.

- The adaptation of the task happens from the cocking to the acceleration phase of the throw.

- Preparatory adjustments may influence the transfer of energy to the ball.

$\begin{array}{ll}\text { ABBREVIATIONS } \\ \text { AAS } & \text { Angulus acromialis of the scapula } \\ \text { ACP } & \text { Acromion process } \\ \text { AIS } & \text { Angulus inferior of the scapula } \\ \text { BMI } & \text { Body Mass Index } \\ \text { C7 } & \begin{array}{l}\text { Spinous process of the } 7^{\text {th }} \\ \text { cervical vertebra }\end{array} \\ \text { LEH } & \text { Lateral epicondyles of the } \\ \text { humerus } & \\ \text { LPS } & \text { Left posterior superior iliac spines } \\ \text { RPS } & \begin{array}{l}\text { Rigth posterior superior iliac } \\ \end{array} \\ \text { Spines }\end{array}$

PUBLICATION DATA

Received 21092020

Accepted 22022021

Published 01062021

\begin{abstract}
BACKGROUND: In handball, speed and accuracy are essential characteristics for the performance of throwing. AIM: To verify the effects of manipulation of task constraints during the throws on kinematic variables in amateur handball players.

METHOD: 18 amateur handball players (18-27 years) made 10 throws to the target with a focus on speed and 10 throws with a focus on accuracy. The kinematic analysis of the throwing was performed, and the Student's t-test was used.

RESULTS: Greater velocity, and hand, acromion, and iliac spines trajectories for throws with a focus on speed in cocking phase was observed. During the acceleration phase, there was greater velocity, and trajectory of the right upper posterior iliac spine, and less time and hand, acromion, and left upper posterior iliac spines trajectories for throws with a focus on speed. The throw with a focus on speed showed greater shoulder and elbow angles at the beginning, and greater elbow angle at the end of throwing.

CONCLUSION: The manipulation in the focus of the throw influenced the movement strategy from the cocking phase to the acceleration phase according to the movement intentionality, with most of the variables presenting greater values in the throw with a focus on speed.
\end{abstract}

KEYWORDS: Handball | Overarm | Motor control | Kinematics

\section{INTRODUCTION}

Handball is a team sport that involves the use of defensive and offensive actions, such as lateral displacements, markings, blocks, ball passes, feint, receptions, and throws. ${ }^{1}$ The need to improve technical actions is evident at all levels of performance in this sport, especially in professional practice. Among the offensive actions that are part of the fundamentals of the sport is throwing, one of the most important actions for characterizing shots to the goal. ${ }^{2}$ Several variables make up the throw and determine the different motor strategies that directly influence the performance of handball players, such as the demand for greater speed or accuracy. ${ }^{3}$

Speed and accuracy are essential characteristics of throws by handball athletes. It is known that the higher the speed of the ball, the lower the accuracy for hitting the target. ${ }^{4}$ However, trained sportsmen can throw the ball accurately at a speed that corresponds to $85 \%$ of the speed achieved in shots that prioritize speed. ${ }^{3}$ When the focus of throws was on the accuracy, the speed of the ball and body segments (wrist, elbow, shoulder, and hip) was reduced in experienced handball players, although the timing of movements of body

\begin{tabular}{l|l|l|l|l}
\hline Ribeiro et al. & 2021 & VOL.15 & N.2 & https://doi.org/10.20338/bjmb.v15i2.198
\end{tabular}


segments had not changed. ${ }^{5}$ Accurate throws require coordinated movements of the torso and upper limb, with great variability in speed, magnitude, and trajectory of the movement so that adjustments are made to hit the target. ${ }^{6}$ Fast throws require greater linear shoulder speed, range of motion of the upper and lower torso, and rotation speed of the lower torso. ${ }^{7}$ Considering that trained handball players change speed, magnitude, and trajectory of body segments during the movements and that they unaltered movement time when instructions changed, it is not clear if these changes in the movement happen in cocking, acceleration, or both phases of throwing when the focus is on speed or accuracy.

Changes in task demands, such as throwing with a focus on accuracy and on speed, can be explained by the Dynamic System Approach, which considers the individual, environment, and the task as factors that influence the adopted motor strategy. ${ }^{8}$ Thus, it is expected that this study will contribute to the understanding of some movement strategies concerning the upper extremity in the face of manipulations in the restrictions of the task for a group of individuals who train to throw in the context of amateur sports. Therefore, the study aimed to verify the effects of manipulation of task constraints during the throws on kinematic variables in amateur handball players during the execution of throws with a focus on speed and accuracy. This study hypothesized that amateur players would have a greater mean velocity and angles amplitude in the throw with a focus on speed than in the throw with a focus on accuracy.

\section{MATERIAL AND METHODS}

Eighteen male amateur handball players, with a mean age of 23.44 years $(\mathrm{SD}=2.87)$, a mean body mass of $79.56 \mathrm{~kg}(\mathrm{SD}=8.69)$, a mean height of $1.80 \mathrm{~m}(\mathrm{SD}=0.07)$, and a mean of Body Mass Index (BMI) of $24.63 \mathrm{~kg} / \mathrm{m}^{2}$ (SD=2.27), participated in this crosssectional study with a non-probabilistic sample. The mean frequency of training was 1.85 days per week $(S D=1.18$,) during 1.575 hours per day of training $(S D=0.41)$, resulting in a mean of weekly training volume of 3.2 hours $(S D=3.07)$. Inclusion criteria were male amateurs players between 18 and 30 years old; right-handed; with a normal and painless range of motion of the shoulder, elbow, and wrist joints; body mass index (BMI) lower or equal to $29.9 \mathrm{~kg} / \mathrm{m}^{2}$; handball practice of at least 6 months; training frequency at least once a week for one and a half hour. Exclusion criteria were history of surgery, injury or dysfunction in the shoulder complex; injury in the lower limbs that compromised the maintenance of orthostatic posture; subluxation of glenohumeral joint; rheumatoid, degenerative, or neurological disease, diabetes mellitus, fibromyalgia, or uncontrolled hypertension. This study was approved by the Ethics Committee on Research (reference 3.411.617), and participants signed an Informed Consent Form previously to the experiment.

For kinematic analysis, the same researcher prepared all participants fixing $10 \mathrm{~mm}$ diameter reflective spherical markers in anatomical references on the right hemibody: acromion process (ACP), lateral epicondyles of the humerus (LEH), ulnar styloid processes (USP), spinous process of the $7^{\text {th }}$ cervical vertebra (C7), angulus acromialis of the scapula (AAS), angulus inferior of the scapula (AIS), right and left posterior superior iliac spines (RPS and LPS).

Participants stayed in standing positions within the calibrated volume $(1.082 \mathrm{x}$ $\left.1.837 \times 0.976 \mathrm{~m}^{3}\right)$, and three meters away from a one-meter-diameter target ${ }^{9}$ composed of 
five concentric circles with a radius equivalent to $10,20,30,40$, and $50 \mathrm{~cm}$, which height was adjusted according to the participant's height. This target was used to give visual information about the throw with a focus on accuracy and a throw with a focus on speed. The projectile used was a tennis ball of about $100 \mathrm{~g}$ in mass and $21 \mathrm{~cm}$ in the perimeter. ${ }^{9}$ The distance between the target and the calibrated volume space was 3 meters. A handball ball was not used because we would like to use a previously published and appropriate tool to assess throws to the target. We, therefore, found the task used in this study and, to keep its properties, we used the tennis ball.

Two different types of throws performed with the dominant upper extremity were assessed: throw with a focus on accuracy and throw with a focus on speed. Participants received different instructions to throw the ball in the target for each type of throwing. We instructed participants to perform the throw of speed throwing the ball with their maximum speed and strength, and with no concerns in which part of the target the ball would hit it. To perform the throw of accuracy, we instructed participants to throw the ball in the center of the target with no instruction about how much speed and strength they should use to perform it. Because the target was different between throws with a focus on accuracy and speed, the rate of hit was not calculated. Participants were allowed to perform two attempts of each throw as a familiarization procedure before the data collection. Furthermore, participants were instructed to remain within the $80 \mathrm{~cm} \times 100 \mathrm{~cm}$ area delimited on the floor. Each participant performed 10 throws with a focus on accuracy and 10 throws with a focus on speed, with a 10-minute rest period between the types of throws. Participants began performing throws with a focus on accuracy followed by performing throws with a focus on speed because we observed in the pilot studies that the motor strategies used in the throw with a focus on accuracy were influenced when players performed previously the throw with a focus on speed.

Four cameras SONYTM (model DCR-sx21), with a frequency of acquisition of 60 $\mathrm{Hz}$, coupled on adjustable tripods were used in this experiment. High and distance of cameras were adjusted according to the experiment to give a reliable and accurate sampling of data. Two cameras were placed on the right side and two cameras were placed behind the participant to film the experiment. A LED light trigger was used as a synchronizer and it was activated for each verbal command to ensure the subsequent synchronization between the cameras.

Images were analyzed frame by frame using the software Dvideow $5.0^{\mathrm{TM}}$. The kinematic data were filtered using a fifth-order Butterworth filter with a cutoff frequency of 6 $\mathrm{Hz}$, and the kinematic variables were calculated using the software Matlab ${ }^{\mathrm{TM}}$ R2014a.

Kinematic variables were calculated between the start and the end of cocking and acceleration phases of the throw. The cocking phase starts from rest and ends at the greatest angle of shoulder elevation and smallest angle of elbow flexion; the acceleration phase begins at the end of the cocking phase and ends when the ball is released. ${ }^{7}$

The hand trajectory was determined as the path taken by the styloid process marker between the beginning and the end of the movement in each phase. Movement time was calculated as the difference in time(s) between the beginning and the end of each phase of throws. Mean velocity was calculated from the ratio between the norm of distance traveled by the styloid process marker and the movement time. Acromion, RPS, and LPS trajectories were determined as the path taken by the ACP, RPS, and LPS markers between the beginning and the end of the movement in each phase, respectively. Shoulder angles (C7/ACP/LEH) and elbow angles (ACP/LEH/USP) were calculated using the 
landmarks necessary to obtain internal angles. RPS/ACP was calculated as the ratio between RPS and ACP trajectories, as LPS/ACP as a ratio between LPS and ACP trajectories. The closer to 0 , the bigger was the dissociation between the pelvic and scapular girdles.

The normality of the data was tested using the Shapiro-Wilk test. The Paired Samples t-Tests were performed for kinematics variables in cocking and acceleration phases to compare throws with a focus on speed and accuracy. Effect size values were calculated by Cohen's $d$. SPSS-19 statistical software was used for all analyses, adopting a significance level of $5 \%$.

\section{RESULTS}

For the cocking phase, hand trajectory $(p=0.004 ; d=0.4)$, mean velocity $(p<0.001$; $d=0.06$ ), acromion trajectory ( $p<0.001 ; d=0.1)$, LPS trajectory $(p<0.001 ; d=0.1)$ and RPS trajectory $(p<0.001 ; d=0.1)$ were greater for throw with a focus on speed than for throw with a focus on accuracy. There were no significant differences for the movement time $(p=0.102 ; d=0.03)$, LPS/ACP $(p=0.066 ; d=0.1)$ and the RPS/ACP $(p=0.082 ; d=0.1)$ variables (table 1).

For the acceleration phase, mean velocity $(p<0.001 ; d=0.3)$, RPS trajectory $(p=0.010 ; d=0.1)$, and RPS/ACP $(p=0.041 ; d=0.08)$ were greater for throw with a focus on speed while movement time $(p=0.003)$ was greater for the throw with a focus on accuracy. There were no significant differences for hand trajectory $(p=0.102 ; d=0.07)$, acromion trajectory $(p=0.121 ; d=0.06)$, LPS trajectory $(p=0.054 ; d=0.06)$, and LPS/ACP $(p=0.198$; $d=0.04)$.

Table 1 - Mean and standard deviation of kinematic variables obtained from the cocking and the acceleration phases of throws of accuracy and speed.

\begin{tabular}{l|cc|cc}
\hline \multirow{2}{*}{ Variable } & \multicolumn{2}{|c|}{ Cocking phase } & \multicolumn{2}{c}{ Acceleration phase } \\
\cline { 2 - 5 } & $\begin{array}{c}\text { Throw with } \\
\text { focus on } \\
\text { Accuracy }\end{array}$ & $\begin{array}{c}\text { Throw with focus } \\
\text { on Speed }\end{array}$ & $\begin{array}{c}\text { Throw with focus } \\
\text { on Accuracy }\end{array}$ & $\begin{array}{c}\text { Throw with } \\
\text { focus on Speed }\end{array}$ \\
\hline Hand trajectory (m) & $1.17(0.25)$ & $1.60(0.52)^{*}$ & $0.84(0.19)$ & $0.95(0.16)$ \\
Movement time (s) & $0.79(0.25)$ & $0.89(0.36)$ & $0.22(0.06)^{* *}$ & $0.15(0.06)$ \\
Mean velocity (m/s) & $1.61(0.52)$ & $1.99(0.68)^{*}$ & $3.96(1.07)$ & $6.82(1.13)^{\star *}$ \\
Acromion trajectory (m) & $0.37(0.16)$ & $0.67(0.34)^{*}$ & $0.26(0.07)$ & $0.31(0.08)$ \\
LPS trajectory (m) & $0.24(0.10)$ & $0.37(0.10)^{*}$ & $0.07(0.04)$ & $0.09(0.04)$ \\
RPS trajectory (m) & $0.22(0.08)$ & $0.33(0.08)^{*}$ & $0.06(0.03)$ & $0.09(0.04)^{* *}$ \\
LPS/ACP & $0.69(0.19)$ & $0.65(0.17)$ & $0.24(0.12)$ & $0.28(0.10)$ \\
RPS/ACP & $0.64(0.21)$ & $0.60(0.18)$ & $0.22(0.11)$ & $0.30(0.10)^{* *}$ \\
\hline
\end{tabular}

LPS: left posterior superior iliac spines; RPS: right posterior superior iliac spines; *: differences between throw with a focus on accuracy and throw with a focus on speed during Cocking phase $(p \leq 0.05)$; **: differences between throw with a focus on accuracy and throw with a focus on speed during Acceleration phase ( $p \leq 0.05)$; LPS/ACP: ratio between LPS and ACP; $R P S / A C P$ : ratio between $R P S$ and $A C P$.

The shoulder angle was greater $(p=0.005 ; d=0.04)$ at the beginning of the cocking phase of the throw with a focus on speed compared to the throw with a focus on accuracy. There were no differences in the shoulder angles in the transition of phases $(p=0.136$; 
$d=0.03)$ and at the end of the acceleration phase $(p=0.591 ; d=0.01)$ between accuracy and speed throws (figure 1a).

(a)

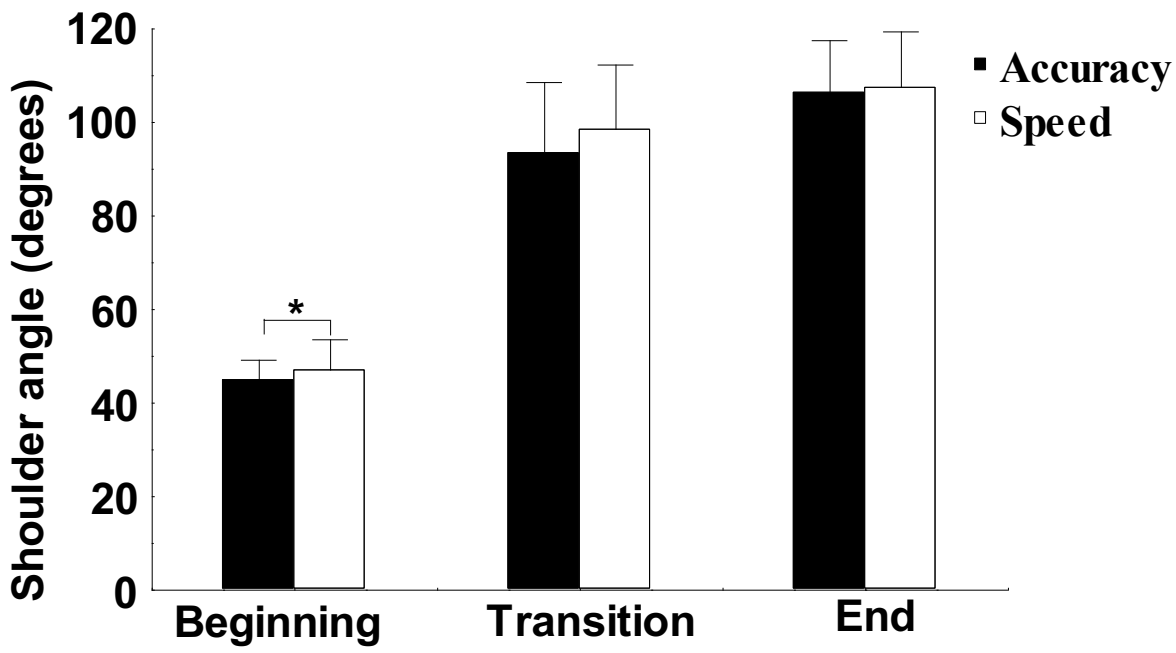

(b)

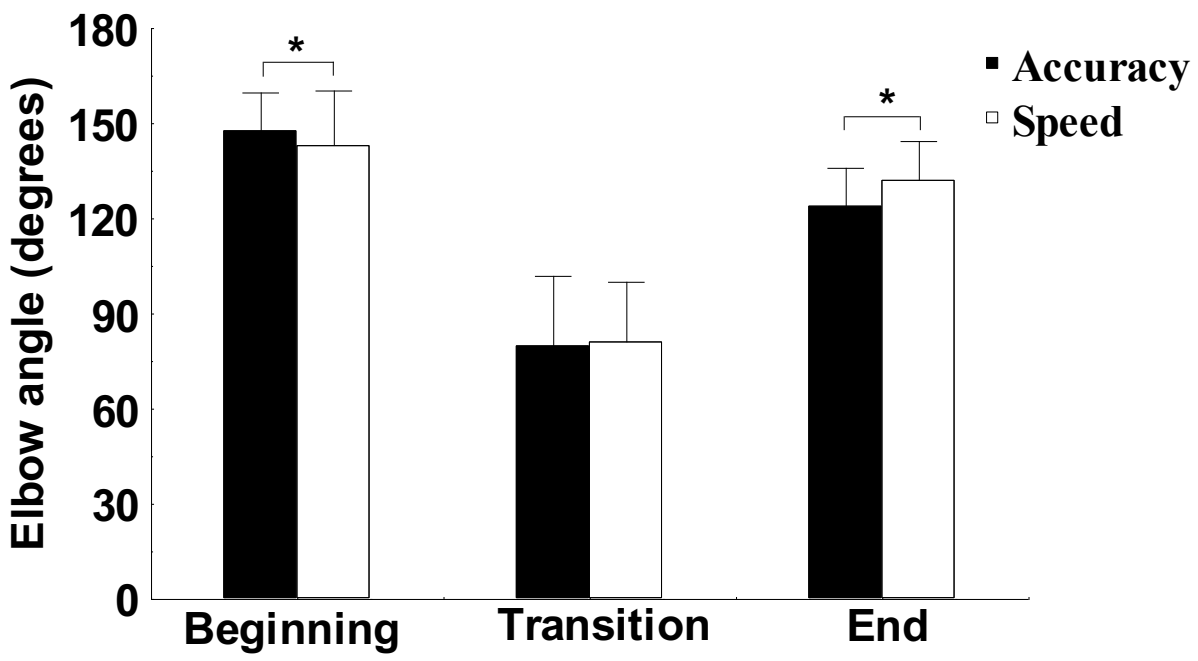

*: difference between throw with a focus on accuracy and throw with a focus on speed $(p \leq 0.05)$

Figure 1. Mean and standard deviation of the shoulder (a) and elbow (b) angles at the beginning of the cocking phase, between phases, and at the end of the acceleration phase for accuracy and speed throws.

The elbow angle was greater at the beginning of the cocking phase $(p=0.01$; $d=0.03$ ) for the throw with a focus on accuracy, and at the end of the acceleration phase $(p=0.02 ; d=0.06)$ for the throw with a focus on speed. There was no difference in the elbow angle in the transition of phases $(p=0.413 ; d=0.01)$ between accuracy and speed throws (figure $1 b$ ).

\section{DISCUSSION}


The study aimed to verify the effects of manipulation of task constraints during the throws on kinematic variables in amateur handball players. The main findings of this study showed that the manipulation of task constraints influenced the movement strategy from the cocking phase to the acceleration phase of throwing. In the cocking phase, results presented greater velocity, and hand, acromion, and iliac spines trajectories for throws with a focus on speed. In the acceleration phase, there were greater velocity and right upper posterior iliac spine trajectory, and less time and hand, acromion, and left upper posterior iliac spines trajectories for throws with a focus on speed. At the beginning of the movement, the players adopted different body positions between throws, with a greater range of motion of the torso and shoulder observed in the throw with a focus on speed. Moreover, to perform the throw with a focus on speed, players adjusted the upper extremity in a posture that required greater shoulder and elbow angles. It is suggested that differences between postures of the upper extremity are the result of different demands for attention and muscle tone for each throw, generating different preparatory adjustments between the throws of accuracy and speed result in different kinematic parameters of velocity, time, and trajectory of body segments.

The verbal command used in the throw with a focus on speed ("With all your strength, anywhere in the target!") possibly influenced the preparation of movement to generate greater strength and speed in its execution, which was confirmed by the results regarding the mean velocity. The verbal command was associated with strength because although speed and strength are different parameters, they are directly interrelated. Verbal stimulation is commonly used for tests that require a high level of applied force and speed and there is an increase in strength performance of trained individuals who were subjected to verbal stimuli during the task. ${ }^{10}$ Studies verified lower speed when the focus was in accuracy when compared with a focus on speed, $, 3,5$ and the change in the way the task information was communicated had influence in the execution of the movement. ${ }^{11}$

In the cocking phase, the trajectory of the hand in the throw with a focus on speed was greater compared to the throw with a focus on accuracy. Greater hand trajectory in the cocking phase implies a greater range of motion of the torso and shoulder. Consequently, there will be a greater potential stored energy transferred to the acceleration phase resulting in greater ball thrust. ${ }^{12}$ During the analysis of filming footage of the throwing, it is evident that there is a greater involvement of the whole body, observed by the greater trajectory of the acromion and iliac spines, with the purpose of increasing the energy transferred to the ball. It was also possible to observe a greater displacement of the participant's upper extremity backward in the throwing with a focus on speed, which can be a strategy adopted to establish greater balance, as well as to ensure greater momentum and, consequently, transfer of force to the ball. ${ }^{13}$

There was no difference for the LPS/ACR and RPS/ACR ratios between the throws in the cocking phase, and the results indicated that during this phase, the shoulder showed greater movement in relation to the hip for both types of the throw. The greater the distance from the hand to the shoulder, the greater the distance between the object and the axis of rotation and, consequently, the greater the object's speed for the same torque application. ${ }^{12,13}$ It is suggested that the torso rotation strategy is used regardless of whether the focus of the throw is on accuracy or strength.

It is known that greater range shoulder and elbow motion results in greater muscular torque when the weight force vector position is farther from the longitudinal 
shoulder axis. ${ }^{14}$ It was expected that during the throwing with a focus on speed, players would present a greater angle of shoulder and elbow in the transition between cocking and acceleration phases of the throw, to increase the distance of the axis of rotation, the force exerted and the velocity of the ball. The opposite was expected for the throw with a focus on accuracy. However, no statistical difference was found between the types of throw for the shoulder and elbow angles in the transition. Study shows that experienced players used what is called as "a single throwing technique" for both throws with focus on accuracy and speed because players did not change the relative timing of movement initiation of different body segments. ${ }^{4}$ Results of the present study complement this statement and indicate that the adaptation of the task happened at the beginning of the cocking phase and throughout its execution, with no significant differences in the transition phase. It is suggested that players preserved some essential elements of the movement, which characterize it as a mature throwing pattern, regardless of whether the task demands accuracy or speed.

During the acceleration phase, there was no difference in the hand and acromion trajectories between the throws. It can be inferred that, even with the instruction to throw with maximum speed and strength, hitting the target requires some level of accuracy. Studies showed that experienced players can throw the ball accurately at higher speeds even if the focus was on throwing as fast as possible and they had more consistent performance when throws velocity was near to maximum force production. ${ }^{3,5}$ In images it was evident that players selected the whip-throw pattern of movement. The whip-throw has a lower trajectory, angular momentum, and final linear velocity than the circular throw. ${ }^{15}$ The circular throw requires a smaller amplitude of shoulder circumduction and expresses a linear component in the acceleration phase, allowing the ball to move towards the target with greater efficiency, but with less velocity. The results of our study show that the similarity of the shoulder and elbow angles between the types of throw in the phase transition are important indicators that there was no difference in the shoulder circumduction between them. However, there was a greater extension of the elbow at the end of the acceleration for the throw with a focus on speed as a strategy to transfer greater potential energy to the ball. ${ }^{13}$

Despite the similarities in the trajectory of the hand and the shoulder angles in the acceleration phase, the throw with a focus on speed had greater velocity and a shorter duration of the movement. It can be inferred that some differences between throws with a focus on accuracy or speed were found because phases were analyzed separately. An example is the timing movement that was similar between throws in previous studies. ${ }^{3,5}$ In addition, there was a greater trajectory of the right superior posterior iliac spine and a higher RPS/ACR ratio, indicating a greater pelvis movement in the acceleration phase in the throw with a focus on speed. When analyzing different strategies involving acceleration of the pelvis and trunk, significant results regarding ball speed and center of mass speed were found. ${ }^{2}$ Therefore, in the throw with a focus on speed, the right hip uses the left hip as the axis of rotation to amplify the transfer of energy from the lower to the upper limbs. This information has an important relationship with the movement pattern of high-performance athletes for the acceleration phase. There exists evidence that there is a proximal-distal sequence at maximum angular velocities, starting with the movement of the proximal articulation of the pelvis rotation, ${ }^{16,17,18,19}$ which has an important influence on improving handball pitch performance. 
The different ways of accounting for the correctness between tasks, in the center of the target when the focus was in accuracy and the entire target when the focus was on speed, were important restrictions of the task to provoke different stimuli and throwing strategies. Moreover, the ball and target were smaller than those that players used to train and it is a movement pattern different from the trained one. Performance of the accuracy task may have a negative influence on handball training, as some strategies adopted for this type of pitch express a greater relationship with the ball's speed, in comparison with the accuracy throw. A task that requires maximum speed would be similar to a shot put, and maximum accuracy is exemplified by the throw of darts. Thus, the two types of throw of this research applied different demands over the upper extremity, which influenced the movement strategies of amateur players, and not as a task that requires maximum speed and/or maximum accuracy.

Our study has strengths, such as the analysis of the cocking and acceleration phases separately which allowed insights about the influence of different focus on throws. Additionally, it was provided not only verbal but also visual instruction because success in action was different in accuracy and speed tasks. For throws with a focus on accuracy, the success was counted when the ball touched the center of the target whereas in the throw with a focus on speed was when the ball touched any place of the target. It also identified some limitations. The biomechanics model used for 3D-reconstruction did not allow us to calculate angles in all planes of trunk, shoulder, and elbow movements, as well as wrist angles. However, we believe that it did not constrain our insights according to the focus of this study. Because the target was outside the calibration volume, it was not possible to analyze random error and precision which could be interesting to confirm how accurate amateur handball players are in this specific task. The determination of space for the execution of the throws was an important factor for the capture of movement. However, the demand related to proprioception has increased, differing from the freedom of movement common to the handball modality. Handball is a team sport with open abilities, and the analyzed tasks of this study were performed in close condition. Moreover, during the game, throws are performed in the presence of teammates, opposition, and goalkeeper. Thus, this study does not represent the throws during the game. However, our results could be used to guide exercises, to train throws in a closed condition, such conditions that might add improvements to the performance of amateur players.

\section{CONCLUSION}

It was concluded that amateur handball players adjusted the throws according to the demands of accuracy and speed, and most of the variables presented greater values in the throw with a focus on speed. The specific training of this sport action in handball may have influenced the performance of the players in this specific action of the throw. Despite this, some aspects found in the throw with a focus on speed stand out, such as the preparatory adjustments, the dissociation between the shoulder and pelvic girdle during the task, final angulation of the elbow, and the transfer of energy from the beginning to the cocking phase. 


\section{REFERENCES}

1. Hespanhol Junior LC, Girotto N, Alencar TN, Lopes AD. Principais gestos esportivos executados por jogadores de handebol. Rev Bras Cienc Esporte. 2012;34(3):727-739. http://dx.doi.org/10.1590/S0101-32892012000300014

2. Wagner $H$, Pfusterschmied J, von Duvillard SP, Müller E. Performance and kinematics of various throwing techniques in team-handball. J Sport Sci Med. 2011;10(1):73-80. https://www.ncbi.nlm.nih.gov/pmc/articles/PMC3737895/

3. Van den Tillaar R, Ettema G. Influence of instruction on velocity and accuracy of overarm throwing. Percept Mot Skills. 2003;96(2):423-434. 10.2466/PMS.97.7.731-742

4. Karadenizli ZI. Inal HS. Meriç B. Aydin M. Bulgan C. Accuracy and velocity of the elite female Turkish handball players. Int J Sports Sci. 2014;4(1):21-26. 10.5923/j.sports.20140401.04

5. Van den Tillaar R, Ettema G. Instructions emphasizing velocity, accuracy, or both in performance and kinematics of overarm throwing by experienced team handball players. Percept Mot Skills. 2003;97(3):731-742. 10.2466/pms.2003.97.3.731

6. Wassinger CA, Sole G, Osborne $H$. The role of experimentally-induced subacromial pain on shoulder strength and throwing accuracy. Man Ther. 2012;17(5):411-415. 10.1016/j.math.2012.03.008

7. Kuhn JE. Throwing, the Shoulder, and Human Evolution. Am J Orthop. 2016;45(3):110114. https://pubmed.ncbi.nlm.nih.gov/26991561/

8. Perone S, Simmering VR. Applications of dynamic systems theory to cognition and development: new frontiers. Adv Child Dev Behav. 2017;52:43-80. https://doi.org/10.1016/bs.acdb.2016.10.002

9. Carratú S, Mazzitelli C, Xavier GF, Sá CSC. Aquisição, Retenção e Transferências de Habilidades Motoras em Crianças Hemiparéticas. Rev Neurocienc. 2012;20(3):360-366. https://doi.org/10.34024/rnc.2012.v20.8247

10. Paes PP, Gantois P, Oliveira GTA, Batista GR, Costa MC, Fortes LS. Estímulos verbais e musicais promovem maior desempenho no teste de $1 \mathrm{rm}$ em mulheres recreacionais no treinamento de força? Rev Bras Cienc Mov. 2019;27(3):67-75. http://dx.doi.org/10.31501/rbcm.v27i3.10010

11. Nascimento LR, Caetano LCG, Freitas DCMA, Morais TM, Polese JC, Teixeira-Salmela LF. Diferentes instruções durante teste de velocidade de marcha determinam aumento significativo na velocidade máxima de indivíduos com hemiparesia crônica. Braz J Phys Ther. 2012;16(2):122-127. https://doi.org/10.1590/\$1413-35552012005000008.

12. McGuinnis PM. Biomecânica do Esporte e Exercício. 3th ed. Porto Alegre, RS: Artmed; 2002. $448 \mathrm{p}$.

13. Okuno E, Fratin L. Desvendando a física do corpo humano: Biomecânica. 2nd ed. Barueri, SP: Manole; 2017. 224 p. 
Brazilian Journal of Motor Behavior

14. Carvalho RP, Tudella E, Savelsbergh GJP. Spatio-temporal parameters in infant's reaching movements are influenced by body orientation. Infant Behav Dev. 2007;30(1):2635. 10.1016/j.infbeh.2006.07.006

15. Van den Tillaar R, Zondag A, Cabri J. Comparing performance and kinematics of throwing with a circular and whip-like wind up by experienced handball players. Scand J Med Sci Sports. 2013;23(6):373-380. 10.1111/sms.12091

16. Van den Tillaar R, Cabri J. Gender differences in the kinematics and ball velocity of overarm throwing in elite team handball players. J Sports Sci. 2012;30(8):807-813. http://dx.doi.org/10.1080/02640414.2012.671529

17. Van den Tillaar R, Ettema $\mathrm{G}$. Is there a proximal-to-distal sequence in overarm throwing in team handball? J Sports Sci. 2009;27(9):949-955. http://dx.doi.org/10.1080/02640410902960502

18. Wagner H, Pfusterschmied J, von Duvillard SP, Müller E. Skill-dependent proximal-to-distal sequence in team-handball throwing. J Sports Sci. 2012;30(1):21-29. http://dx.doi.org/10.1080/02640414.2011.617773

19. Wagner H, Pfusterschmied J, Tilp M, Landlinger J, von Duvillard SP, Müller E. Upper-body kinematics in team-handball throw. tennis serve. and volleyball spike. Scand J Med Sci Sports. 2014;24(1):345-354. 10.1111/j.1600-0838.2012.01503.x

Citation: Ribeiro GA, Spinola PHBF, Tucci HT, Carvalho RP. Manipulation of Task Constraints on Throwing of Amateur Handball Athletes. BJMB. 2021. 15(2): 127-136.

Editors: Dr Fabio Augusto Barbieri - São Paulo State University (UNESP), Bauru, SP, Brazil; Dr José Angelo Barela São Paulo State University (UNESP), Rio Claro, SP, Brazil; Dr Natalia Madalena Rinaldi - Federal University of Espírito Santo (UFES), Vitória, ES, Brazil.

Copyright:@ 2021 Ribeiro, Spinola, Tucci and Carvalho and BJMB. This is an open-access article distributed under the terms of the Creative Commons Attribution-Non Commercial-No Derivatives 4.0 International License which permits unrestricted use, distribution, and reproduction in any medium, provided the original author and source are credited.

Funding: This research did not receive any specific grant from funding agencies in the public, commercial, or not-forprofit sectors.

Competing interests: The authors have declared that no competing interests exist.

DOI: https://doi.org/10.20338/bjmb.v15i2.198 